\title{
TEORI UNTUK MEMPEROLEH KETENANGAN HATI
}

\author{
Abdul Kallang \\ abdulkallang01@gmail.com \\ Institut Agama Islam Negeri Bone
}

\begin{abstract}
Abstrak
Upaya yang dapat di tempuh dalam rangka mendapatkan rasa tenang dan tentram adalah dengan senantiasa dzikir kepada Allah, membiasakan membaca alQur'an dan bershalawat, kepada Nabi Muhammad saw, menunaikan shalat lima waktu dan shalat tahajjud, bergaul dengan orang-orang yang shaleh, berbuasa mendengarkan ceramah-ceramah agama, segera bertaubat, sabar, tawakkal dan tawadhu. Baik secara fisik manusia harus selalu melakukan kebaikan maupun secara psikis manusia harus selalu mengingat Allah sehingga secara psikologis antara manusia dan pencipta selalu dekat dan menhasilkan ketengan dalam hati.
\end{abstract}

Kata Kunci: Berzikir, Shalat, Taubat, Sabar, Tawakkal

\begin{abstract}
Efforts that can be taken in order to get a sense of calm and peace is to always dhikr to Allah, get used to reading the Qur'an and pray, to the Prophet Muhammad, to perform the five daily prayers and the midnight prayer, associate with people who pray, fast listening to religious lectures, immediately repent, patience, resignation and tawadhu. Both physically humans must always do good and psychologically humans must always remember God so that psychologically between humans and the creator is always close and produce silence in the heart.

Keywords: Remembrance, Prayer, Repentance, Forbearance, Tawakkal

\section{PENDAHULUAN}

Bersikap Tawadhu (kerendahan hati) ${ }^{1}$ dimana kerendahan hati adalah suatu cahaya yang merupakan inti kepercayaan yang berarti pertimbangan yang teramat dalam segala sesuatu yang di cela atau tauhid dan ma'rifat ${ }^{2}$. orang yang tawadhu menyadari bahwa apa saja yang ia miliki, baik bentuk rupa yang menawan, ilmu pengetahuan, harta kekayaan, maupun Pangkat dan kedudukan, semuanya itu adalah

\footnotetext{
${ }^{1}$ Yunahar Ilyas, Kuliah Akhlak (cet, IV; Yogyakarta, Lembaga Pengkajian dan Pengamatan Islam LPPI, 2001), h. 123.

h. 73 .

${ }^{2}$ Ahmad Mustafa al-Maraghi, Tafsir al-Maragh, Juz III (Cet. I; Semarang: Toha Putra, 1988),
} 
karunia dari Allah swt ${ }^{3}$. sehingga dengan kesadaran seperti itu dia tidak akan menyombongkan diri sesama manusia, apalagi menyombongkan diri terhadap Allah swt. Yang menciptakan alam semesta beserta segala isinya.

Pada saat hamba Allah mau bertaubat maka ada jenis taubat yang dianjurkan adalah taubat nasuha yang mencakupi tiga unsur: Pertama, ia mencakup seluruh dosa sehingga tidak ada satu pun dosa yang tertinggal ${ }^{4}$; kedua, kebulatan tekad untuk itu sehingga tidak tersisa lagi keragu-raguan dan kebimbangan ${ }^{5}$; ketiga, menirukannya dari berbagai hal yang bisa merusak keikhlasan taubat tersebut.

Tawakkal, membebaskan hati dari segala ketergantungan kepada selain Allah dan menyerahkan keputusan segala sesuatunya kepadanya ${ }^{6}$. sikap tawakkal sangat bermanfaat untuk mendapatkan ketenangan hati, sebab apabila seseorang telah berusaha dengan sungguh-sungguh untuk mencapai sesuatu dengan mengarahkan segala tenaga dan membuat perencanaan yang sangat cermat dan detail melaksanakannya dengan penuh disiplin, dan melakukan pengawasan dengan ketat, kemudian kalau mengalami kegagalan dia tidak akan berputus asa. Dia menerimanya sebagai musibah, ujian dari Allah swt yang harus dihadapi dengan sabar ${ }^{7}$.

Senantiasa memelihara kadar keimanan dalam hati, sebab tanpa iman seseorang tidak mungkin merasakan atau mengalami ketenangan hidup yang hakiki. Menurut Yusuf Qardawi yang menyatakan bahwa "Pencerahan Spritual Sukses Membangun Hidup Damai dan Bahagia". Bahwa ketenangan hidup sangat dipengaruhi untuk iman, sebab; pertama, iman adalah fitrah manusia; kedua ${ }^{9}$, orang yang beriman memiliki tujuan hidup yang benar; ketiga iman akan melahirkan rasa aman; keempat, iman akan menumbuhkan optimis.

Untuk memperoleh suatu kebahagiaan membutuhkan pengorbanan yang besar dalam segala hal, begitu pula dalam mendapatkan rasa ketenangan, ketenteraman dalam hidup di dunia dan di akhirat harus melalui beberapa jalan yang ditempuh untuk memperolehnya. Ketika hal itu sudah di jalani maka secara tidak langsung hati akan senantiasa merasa tenang, aman dan puas atas keputusan dan ketetapan Allah sekalipun itu sangat pahit.

\footnotetext{
${ }^{3}$ Lihat QS. An-Nahl (16), 53.

${ }^{4}$ Ibnu Qayyim al-Jauziyah, Ibnu Rajab al-Hambali dan Imam al-Gazali, Tazkiyatun Nafs diterjemahkan oleh Imtihan Asy-Safi'I dengan judul, Tazkiya an-Nafs (konsep penyucian Jiwa Menurut Para Salaf), (Cet. VII; Solo: Pustaka Arafah, 2002), h. 148.

5 A. Rivay Siregar, Tasawuf dari Sufisme Klsik Ke Neo Sufisme (Cet. II; Jakarta: PT. Raja Grafindo Persada, 2002), h. 255.

${ }^{6}$ A. Rivay Siregar, Tasawuf dari Sufisme Klsik Ke Neo Sufisme, h. 255

${ }^{7}$ Yunahar Ilyas, Kuliah Akhlak, h. 44

${ }^{9}$ Rusli Amin, Pencerahan Spiritual Sukses Membangun Hidup Damai dan Bahagia (Cet. II; Jakarta Selatan: PT. Raja Grafindo Persada, 2003), h. 48.
} 


\section{PEMBAHANSAN}

\section{A. Menurut Psikologi}

Kecemasan adalah ketakutan terhadap hal-hal yang belum terjadi. Perasaan cemas biasanya muncul apabila berada dalam suatu keadaan yang akan merugikan dan dirasakan mengancam, dimana merasa tidak berdaya untuk menghadapinya ${ }^{12}$. padahal sebenarnya apa yang di cemaskan belum tentu akan terjadi. Dengan demikian rasa cemas sebenarnya adalah ketakutan yang diciptakan sendiri.

Pandangan Psikologi terhadap masalah kecemasan cukup beraneka ragam. Karena rasa cemas adalah penyebab utama munculnya berbagai penyakit kejiwaan seperti putus asa, gelisah, takut yang berlebihan, dendam, iri hati dan sombong serta bosan menjalani hidup. Oleh karena itu untuk memberikan rasa aman, tenang dan tentram pada kondisi kejiwaan seperti diatas, psikologi memberikan beberapa terapi, adalah sebagai berikut:

\section{a) Relaksasi}

Yang bertujuan untuk menimbulkan rasa tenang melalui teknik pengencangan dan pengendaran otot -otot tubuh, seperti pengendoran otot tangan, kaki, muka, leher, dan otot rongga dada. Hal ini dapat dilakukan dalam aktivitas olah raga.

b) Pernafasan

Yang bertujuan untuk melepaskan himpitan-himpitan masalah yang tertumpuk di dalam dada dan otak. Hal ini dapat dilakukan dengan menarik nafas yang panjang secara rileks, membuang semua masalah yang menghimpit dada melalui pernafasan yang dikeluarkan.

c) Tingkah laku ${ }^{15}$

Yang bertujuan untuk menghilangkan berbagai bentuk dan kecemasan dengan jalan melatih diri untuk menghadapinya, baik sedik demi sedikit untuk meninggalkan hal-hal buruk yang pernah dilakukannya dengan mencoba melakukan hal-hal yang bermanfaat dalam hidup dan tidak berangan-angan yang panjang.

\section{B. Menurut Tasawuf}

Sebagaimana diketahui bahwa tasawuf adalah jalan yang ditempuh untuk senantiasa membersihkan diri dengan berjuang memerangi hawa nafsu, mencari jalan kesucian dengan ma'rifat menuju keabadian, saling mengingatkan antara sesama manusia serta berpegang teguh pada janji Allah dan mengikuti syariat Rasulullah dalam mendekatkan diri dalam mencapai keridhahan-Nya. ${ }^{16}$

Baik aliran psikologi maupun aliran sufisme sepakat, bahwa dzikir yang dilaksanakan secara teratur dan benar akan membuahkan rasa ketenteraman,

${ }^{12}$ Hanna Jumhana Batasman, Integrasi Psikologi dengan Islam ( Cet. I; Yogyakarta : Pustaka Pelajara, 1995), h. 156.

${ }^{15}$ Hanna Jumhana Batasman, Integrasi Psikologi dengan Islam

${ }^{16}$ Rosihan Anwar dan Mukhtar Solihin, Ilmu Tasawuf ( Cet, II: Bandung : CV Pustaka Setia, 2004), h. 14. 
ketenangan dan kebahagiaan. ${ }^{17}$ Setiap orang pasti mendambakan ketenangan batin, dan untuk mencapai ketenangan batin bukanlah sesuatu yang mustahil.

Dengan selalu mengingat Allah, hati akan tentram, sebaliknya ketika tidak ingat kepada Allah, hati akan kering dan gersang. Sejauh mana seorang hamba bersungguh-sungguh ingin hidup dalam ketentraman hati, akan sangat terlihat dari berapa banyak waktu di gunakan untuk mengingat Allah. Dengan dzikir kepada Allah akan memberikan daya terapi yang potensial untuk menunjukkan ketenangan dan ketentraman hati. Mengingat betapa pentingnya ibadah dzikir sebagai salah satu cara untuk mendapatkan rasa tenang dan tentram yang meliputi hampir semua bentuk ibadah dan perbuatan..

Dzikir (ingat) kepada Allah adalah ingat akan kebesaran nikmat, ancaman atau siksa Allah. Secara luas dengan ingat kepada Allah ialah dengan mengerjakan seluruh yang diperintahkan dan takut akan melanggar larangan-Nya. ${ }^{1}$ Oleh karena itu, dengan banyak berdzikir manusia akan selalu merasa perbuatannya selalu di perhatikan oleh Allah, sehingga ia takut untuk melanggar segala macam aturan yang di perintahkan kepadanya. Sebagaimana dalam sabda Nabi saw yang diriwayatkan oleh Muslim, sebagai berikut :

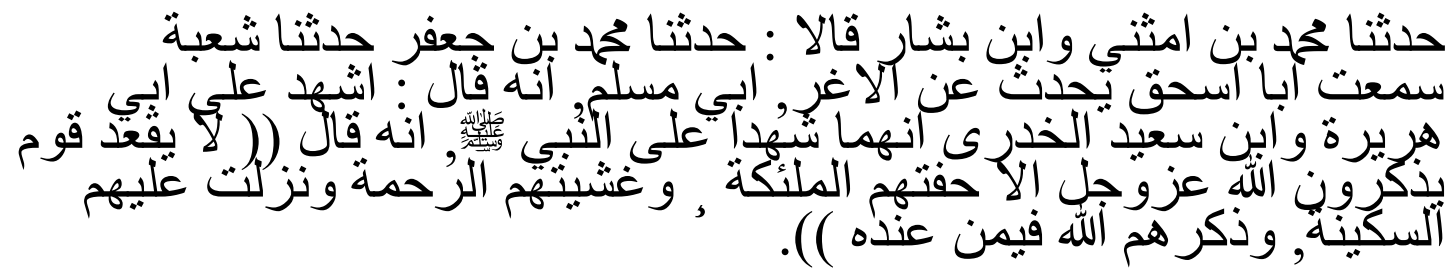

Artinya: diriwayatkan oleh Muhammad bin Mutsana dan ibnu Basyar berkata: diriwayatkan juga oleh Muhammad Ja'far diriwayatkan oleh Syu'bah dia mendengarkan Aba Ishaq hadis ini dari Igrar, Abi Muslim, sesungguhnya berkata: Sesungguhnya tidaklah berkumpul duduk suatu kaum mengucapkan dzikir kepada Allah, maka melingkungi akan mereka para malaikat-malaikat dan meliputi mereka akan rahmat, dan turun atas mereka sakinah (rasa tenteram dan tenang tang mendalam), dan Allah mengingat mereka pada sisiNya. Diriwatkan oleh Muslim). ${ }^{19}$

Betapa besarnya ibadah dzikir, jika di lakukan karena selain dapat menentramkan hati, dzikir juga akan memberikan penerangan dalam hati dari kegelapan. Dengan melakukan dzikir, manusia akan mencapai derajat ketakwaan atau derajat tertinggi dalam keimanan. Karena dengan banyak berdzikir manusia akan

\footnotetext{
${ }^{17}$ Al-Imam Abi al-Hasan Muslim bin al-Hajjaj al-Qusyairiyyah an-Naisaburi, Shahih Muslim, Juz IV (Berut: Dar al-Kitab al-Ilmiyah : 1992 M/1413H), h. 48.

${ }^{19}$ Al-Imam Abi al-Hasan Muslim bin al-Hajjaj al-Qusyairiyyah an-Naisaburi, Shahih Muslim, Juz IV (Berut: Dar al-Kitab al-Ilmiyah : 1992 M/1413H)
} 
lebih dekat kepada Allah, dengan terbukanya tabir yang menghalangi untuk dekat kepada-Nya, sekaligus dengan memperbanyak dzikir manusia akan terhindar dari segala macam noda dan kotoran yang tertimbun di dalam hati yang berdzikir. Dengan begitu seseorang bisa berharap agar dzikirnya selalu meningkat terus sehingga mencapai kepada suatu keadaan dimana dzikir itu akan keluar tanpa sengaja. Kalau sudah mencapai tingkat demikian, maka hanya Allah-lah yang ada dalam setiap gerak badannya.

Dalam rangka upaya menjadikan dzikir sebagai kebutuhan hidup dan pembinaan suasana yang kondusif untuk mengabaikan nafs muthmainnah dalam diri, maka di perlukan sikap disiplin dan istiqamah dalam lima hal, yakni:

a. Mu'ahadat, yakni selalu ingat dan sadar akan janji yang telah diikrarkan kepada Allah, sejak di alam arwah manusia telah mengikat janji bahwa ia akan taat dan setia kepada Allah, sebagai satu-satunya pencipta dan pemelihara, sebagai satu-satunya yang layak dan wajib di sembah. ${ }^{22}$

b. Muhasabah, yang memikirkan, menganalisa dan memperhitungkan secara teliti dan jujur segala apa yang sudah dan akan dilakukan keberanian melakukan muhasabah akan menuntun seseorang untuk lebih berhati-hati dalam segala aspek kehidupan, teliti dalam mengambil sikap dan tindakan yang akan datang. ${ }^{24}$

c. Mu'agabah, yakni pemberian sanksi kepada diri sendiri apabila kenyataan hasil muhasabah menunjukkan nilai kurang walau sekecil apa pun. Tujuan pemberian sanksi kepada diri sendiri agar lebih sadar diri akan adanya sanksi yang lebih dekat di akhirat nanti, seperti dengan berpuasa.

d. Muragabah, adalah kesadaran rohaniah tentang kebersamaan dengan Allah dalam segala suasana. Artinya dimana saja berada, dalam suasana dan kondisi yang bagaimanapun kebersamaan dengan Allah harus di hidupkan dalam hati.

e. Mujahada, yakni kemauan dan kemampuan dan mengarahkan segala daya dan upaya secara sungguh-sungguh untuk meninggalkan segala godaan hawa nafsu. ${ }^{27}$

Adapun manfaat yang diperoleh dari pelaksanaan dzikrullah ${ }^{28}$ adalah: $^{2}$ Pertama, dzikrullah sebagai sarana komunikasi untuk mendekatkan diri kepada Allah $^{29}$; kedua, menjadi golongan yang unggul ${ }^{30}$; ketiga, Allah menyediakan ampunan dan pahala yang banyak bagi mereka yang melakukan dzikrullah ${ }^{31}$;

\footnotetext{
${ }^{22}$ Lihat Q.S. Al-An'Am (6) : 163.

${ }^{24}$ Lihat Q.S. Al-Hasyr (59) : 18.

${ }^{27}$ A. Rivay Siregar, Tasawuf dari Sufisme Klsik Ke Neo Sufisme, h. 257

${ }^{28}$ Hanna Juhamna Bustaman, Integrasi Psikologi Dengan Islam, 159

${ }^{29}$ Lihat q.S. Al-Baqarah(2) ; 152.

${ }^{30}$ Lihat Q.S. Al-Ahzab (33) :35.

${ }^{31}$ Hanna Juhamna Bustaman, Integrasi Psikologi Dengan Islam, 159
} 


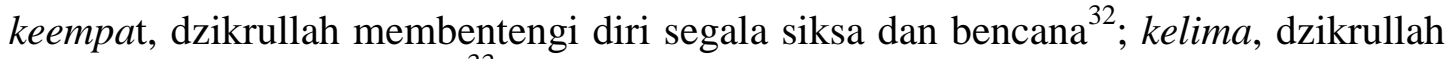
menunda datangnya kiamat ${ }^{33}$.

Semakin banyak mengingat Allah, maka pikiran semakin terbuka, hati semakin tentram, jiwa akan semakin bahagia serta nurani merasa aman, damai sentosa. Hal itu karena dalam mengingat Allah terkadang nilai-nilai ketakwaan, keyakinan, ketergantungan, kepasrahan, baik sangka dan pengharapan kebahagiaan dari-Nya ${ }^{34}$.

Selain dzikir kepada Allah dalam rangka mewujudkan ketenangan dan ketentraman dalam hati manusia, hendaknya juga ditempuh jalan sebagai berikut:

1. Harus selalu membaca kitab suci (al-Quran) dan membaca shalawat dengan sebanyak banyaknya.

2. Shalat malam (tahajjud/hajat) disaat manusia semuanya sedang tidur. Kedamaian $\mathrm{j}$ iwa dan ketenangan akal serta kondisi dari kelonggaran dan kedamaian jiwa yang diciptakan shalat memberikan pengaruh pengobatan yang cukup penting dalam mengarungi tajamnya ketegangan-ketegangan syaraf yang tumbuh karena tekanan-tekanan hidup sehari-hari dan dalam meringankan kegelisahan yang diderita sebagian orang ${ }^{35}$. berdirinya seorang hamba shalat dihadapan Allah SWT dalam keadaan khusyu' dapat memperkuat dirinya dalam memunculkan kekuatan rohani sehingga timbullah. Rasa kebeningan rohani, ketenangan hati dan keamanan jiwa ${ }^{36}$.

3. Berkawanlah atau bergaullah dengan orang-orang yang shaleh yang selalu berbuat baik dalam hidupnya ${ }^{37}$.

4. Harus memperbanyak berzikir, seperti baca tasbih, tahlil dan istiqrar ${ }^{38}$.

5. Puasa dalam mengikuti sunnah Rasul saw, yaitu puasa sunnah pada hari senin dan kamis serta dalam hari yang lain. Puasa memiliki faedah psikologis yang banyak, didalamnya terdapat pendidikan dan pengajaran bagi jiwa dan terapi bagi banyak dari penyakit jiwa dan tubuh ${ }^{40}$.

6. Mengajarkan ceramah-ceramah agama atau dakwah islamiyah dari orangorang yang shaleh dan ma'rifat. Sebagaimana ungkapan Syaikh Ahmad bin Athallah bahwa fatwa-fatwa agama itu ibarat seperti makanan bagi para

${ }^{32}$ Hanna Juhamna Bustaman, Integrasi Psikologi Dengan Islam, 159

${ }^{33}$ Hanna Juhamna Bustaman, Integrasi Psikologi Dengan Islam, h. 160.

${ }^{34}$ Aidh Al-Qarni, Tsalasuna Sababah Li As-Sa'dah diterjemahkan oleh Muhammad bin Qusry dengan judul, Tips Bahagia Dunia Akhirat (Cet. III; Solo: Pustaka Arafah, 2005), h. 85.

${ }^{35}$ Utsman Najati, Jiwa Manusia Dalam Sorotan Al-Qur'an (Cet. I; Jakarta: CV. Cendekia Sentra Muslim, 2002), h. 26.

${ }^{36}$ Amin An-Najr, Mengobati Ganguan Jiwa (Cet. I; Jakarta: PT. Mizan Publika, 2004), h. 82.

${ }^{37}$ Mudzakkir Mukhtar, Hati Manusia (Cet. I; Jakarta: M.M. Jaya, 1995), h. 66.

${ }^{38}$ Mudzakkir Mukhtar, Hati Manusia

${ }^{40}$ Utsman Najati, Jiwa Manusia Dalam Sorotan Al-Qur'an 
pendengar yang membutuhkan siraman rohani dalam menyejukkan hatinya, ungkapan tersebut menjelaskan bahwa segala macam ucapan agama atau fatwa-fatwa agama dari orang ma'rifat merupakan santapan bagi ruh atau hati orang-orang yang mendengar dan membutuhkannya ${ }^{41}$.

7. Bersikap sabar dalam berbagai macam cobaan dan rintangan dalam kehidupan ini. Faedah yang ditimbulkan dari sabar dalam mendidik jiwa dan memperkuat pribadi (jati diri) menambah kemampuan seseorang memikul kesulitan dalam menghadapi problematika hudup dan bebannya ${ }^{242}$, bencana zaman dan musibah-musibahnya serta untuk membangkitkan kemauan untuk melanjutkan perjuangan dalam meningkatkan kalimat Allah subhanallah wata'ala dalam firmannya. Q.S. al-Baqarah (2): 45; 153 : Q.S. al-Imran(5): 200).

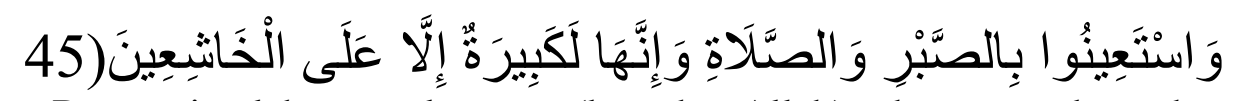

Terjemahnya: Dan mintalah pertolongan (kepada Allah) dengan sabar dan (mengerjakan) shalat (wasta'iinuu bish-shabri wash-shalaati). Dan sesungguhnya yang demikian itu sungguh berat, kecuali bagi orang-orang yang khusyuk ( innahaa lakabiiratun illaa 'alal khaasyi'iin),

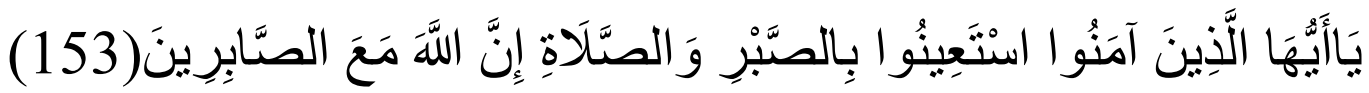

Terjemahnya: Hai orang-orang yang beriman, mintalah pertolongan (kepada Allah) dengan sabar dan (mengerjakan) shalat, sesungguhnya Allah beserta orang-orang yang sabar.

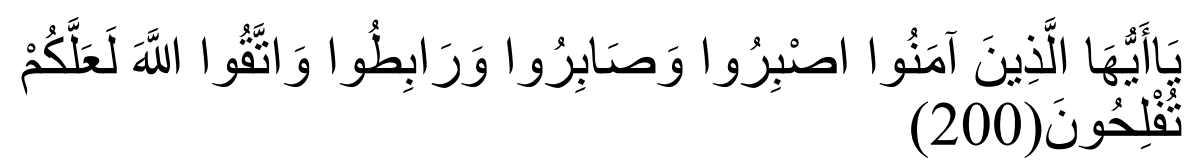

Terjemahnya: hai orang-orang yang beriman, bersabarlah kamu dan kuatkanlah kesabaranmu dan tetaplah bersiap siaga (di perbatasan negerimu) dan bertakwalah kepada allah supaya kamu beruntung.

\section{Hakekat Suatu Ketenangan}

Adapun hakekat muthmainnah yang membuat qalbu merasa damai bersamaNya, terjadi ketika merasa tentram menerima berita yang disampaikan oleh rasul-Nya

\footnotetext{
${ }^{41}$ Ahmad bin Athaillah, al-Hikmah (Cet. I; Surabaya: al-Ihsan, 1991), h. 83.

${ }^{42}$ Lihat Utsman Najati, Jiwa Manusia Dalam Sorotan Al-Qur'an, h. 326.
} 
dalam pengenalan akan asma-asma, sifat-sifat, dan kesempurnaan-Nya, sehingga ia menyebutnya dengan penuh penerimaan, kepasrahan dan kepatuhan. selain itu ia merasa tenteram kepada berita yang berasal diri-Nya tentang peristiwa dan keadaan setelah kematian, mulai situasi di dalam barzakh sampai pada betapa dahsatnya keadaan pada hari kiamat ${ }^{44}$. dan juga merasa tentram kepada perintah dan laranganNya dengan penuh kesetiaan dan ketulusan dalam menjalaninya ${ }^{45}$.

Ayat-ayat muthmainnah yang mana pada ayat-ayat tersebut memberikan indikasi bahwa hati yang padanya ditempatkan ketenangan hati orang-orang yang beriman. Sekalipun tingkat keimanan paling rendah ia akan tetap membuat hati tenang ${ }^{46}$. hanya saja tingkat keimanan sangat menentukan tingkat ketenangan dan kekaleman yang ditimbulkan semakin rendah tingkat keimanan seseorang, maka akan semakin rendah pula ketenangan dan kekaleman yang ditimbulkan dan begitu pula dengan sebaliknya. Berikut ini gambaran tingkatan keimanan tersebut, sifat terpuji yang ditimbulkannya sifat ketenangan hati yang dihasilkannya. ${ }^{47}$

Berdasarkan dari uraian diatas tentang tingkat keimanan yang melahirkan ketenangan, menunjukkan bahwa betapa pentingnya keimanan dalam diri seseorang. Sebab semakin tinggi keimanan seseorang akan semakin tinggi pula rasa ketenangan dan ketentraman yang akan ditimbulkannya. Ia akan senantiasa merasa aman, tenteram dan bahagia baik ketika berinteraksi dengan Allah sebagai Sang khaliq maupun ketika berinteraksi dengan sesama manusia sebagai mahluk sosial.

\section{KESIMPULAN}

Pandangan psikologi dalam rangka mengatasi gangguan-gangguan jiwa yang akhirnya akan melahirkan rasa tenang dan tenteram adalah dengan melakukan relaksasi otot-otot tubuh, latihan pernafasan, serta melakukan terapi tingkah laku. Sedangkan menurut pandangan Tasawuf dalam rangka melahirkan rasa ketenangan dan ketentraman dalam hati adalah senantiasa melakukan dzikrullah.

Hakekat muthmainnah adalah terjadi ketika merasa tenteram menerima berita yang disampaikan oleh rasul-Nya dalam pengenalan akan asma-asma, sifat-sifat dan kesempurnaan-Nya, sehingga ia menyebutnya dengan penuh penerimaan, kepasrahan dan kepatuhan. Disampin juga keimanan yang paling utama dalam rangka menciptakan rasa ketenangan dan ketetnteraman.

${ }^{44}$ Abu Hamid Al-Gazali, Pembuka Pintu Hati ( Cet, I : Bandung : Lentera Hati, 2006), h. 9.

${ }^{45}$ Abu Hamid Al-Gazali, Pembuka Pintu Hati, h. 229.

${ }^{46}$ M. Yaniyullah Delta Auliyah, Melejitkan Kecerdasan Hati dan Otak Menurut Petunjuk AlQur'an dan Neurologi (Cet. I; Jakarta: PT. Raja Grafindo Persada,2005), h. 123.

${ }^{47}$ M. Yaniyullah Delta Auliyah, Melejitkan Kecerdasan Hati dan Otak Menurut Petunjuk AlQur'an dan Neurologi, h. 326-327. Lihat kembali Q.S. Ar-Ra'd (13) : 28. 
Penulis berharap kepada kaum muslimin agar senantiasa menghadapi hidup ini dengan optimis, tanpa harus berkeluh kesah, berputus asa, gelisah dan takut. Dengan membiasakan berdzikir kepada Allah tentang segala nikmat, rahmat, kebesaran dan keagungan-Nya, sehingga keimanan pun bertambah di dalam hati. Ikhlas dan sabar dalam menerima setiap ujian dan cobaan, sebab semua itu pasti ada hikmah di baliknya serta tidak bersikap sombong kepada Allah swt dan sesama manusia ketika memperoleh suatu keberuntungan.

Penulis juga berharap, sekiranya setelah mengetahui hakekat teori ketenangan dalan teks dan konteks ini, diharapkan mampu merealisasikannya dalam kehidupan sehari-hari.

\section{DAFTAR PUSTAKA}

Hanna Jumhana Batasman, Integrasi Psikologi dengan Islam Cet. I; Yogyakarta : Pustaka Pelajara, 1995.

Kartini Kartono dan Dali Galo, kamus Psikologi Cet, I; Bandung : CV. Pionir Jaya, 2000.

Rosihan Anwar dan Mukhtar Solihin, Ilmu Tasawuf Cet, II: Bandung : CV Pustaka Setia, 2004.

Al-Imam Abi al-Hasan Muslim bin al-Hajjaj al-Qusyairiyyah an-Naisaburi, Shahih Muslim, Juz IV Berut: Dar al-Kitab al-Ilmiyah : 1992 M/1413H.

A. Rivay Siregar, Tasawuf dari Sufisme Klsik Ke Neo Sufisme Cet. II; Jakarta: PT. Raja Grafindo Persada, 2002

Aidh Al-Qarni, Tsalasuna Sababah Li As-Sa'dah diterjemahkan oleh Muhammad bin Qusry dengan judul, Tips Bahagia Dunia Akhirat Cet. III; Solo: Pustaka Arafah, 2005.

Utsman Najati, Jiwa Manusia Dalam Sorotan Al-Qur'an Cet. I; Jakarta: CV. Cendeki a Sentra Muslim, 2002.

Amin An-Najr, Mengobati Ganguan Jiwa Cet. I; Jakarta: PT. Mizan Publika, 2004.

Mudzakkir Mukhtar, Hati Manusia Cet. I; Jakarta: M.M. Jaya, 1995.

Ahmad bin Athaillah, al-Hikmah Cet. I; Surabaya: al-Ihsan, 1991.

Yunahar Ilyas, Kuliah Akhlak(cet, IV; Yogyakarta, Lembaga Pengkajian dan Pengamatan Islam LPPI, 2001.

Ahmad Mustafa al-Maraghi, Tafsir al-Maragh, Juz III Cet. I; Semarang: Toha Putra, 1988.

Ibnu Qayyim al-Jauziyah, Ibnu Rajab al-Hambali dan Imam al-Gazali, Tazkiyatun Nafs diterjemahkan oleh Imtihan Asy-Safi'I dengan judul, Tazkiya anNafs (konsep penyucian Jiwa Menurut Para Salaf Cet. VII; Solo: Pustaka Arafah, 2002.

Rusli Amin, Pencerahan Spiritual Sukses Membangun Hidup Damai dan Bahagia Cet. II; Jakarta Selatan: PT. Raja Grafindo Persada, 2003. 
Abdul Hadi bin Hasan WAhbi, Menuju Kesucian Hati Cet. III; Band ung: PT. Remaja Posdakarya, 2004.

Abu Hamid Al-Gazali, Pembuka Pintu Hati Cet, I : Bandung : Lentera Hati, 2006.

M. Yaniyullah Delta Auliyah, Melejitkan Kecerdasan Hati dan Otak Menurut Petunjuk Al-Qur'an dan Neurologi Cet. I; Jakarta: PT. Raja Grafindo Persada,2005. 